\title{
A Study of Interpreting the Future Contingents
}

\author{
Xuejun Wang* \\ School of Philosophy, Beijing Normal University, 19 Xinjiekouwai Street, Beijing, 100875, China \\ *Corresponding Author: Xuejun Wang, School of Philosophy, Beijing Normal University, 19 \\ Xinjiekouwai Street, Beijing, 100875, China
}

\begin{abstract}
I discuss two issues raised by Aristotle's argument about the Sea Battle, one is Aristotle's so-called "conditional necessity", and the other is how to interpret the truth-value of future contingents. The reason why he fell into the dilemma of the determinism was because he incorrectly replaced the proposition about the past with the future contingent. And if we explain the "necessity" and the truth and falsehood of the proposition from the perspective of fact, then there is no question about deterministic problem in Aristotle's discussion. The "necessity" that Aristotle talked about is actually a "factual necessity", which corresponds to the "logical necessity" in the sense of modal logic. In addition, for an event that has not happen in the real world, we can only talk about the truth of the future contingent that describes it from the perspective of hypothesis before it becomes a fact.
\end{abstract}

Keywords: Factual necessity, truth-value, future contingents, hypothesis-revision

\section{INTRODUCTION}

Will the future events occur necessarily? Will human's choice affect the future? A related discussion is the Sea Battle raised by Aristotle concerning about whether there is a sea battle necessarily tomorrow, which is also the debate between determinism and non-determinism. Determinists argue that our future is predetermined and nothing will happen by chance so that a future contingent, "a sea battle will happen tomorrow necessarily", has a certain truth-value, true or false. While nondeterminists consider that there are multiple alternative futures and nothing will happen necessarily, so the truth-value of a future contingent cannot be determined temporarily. In section 2 I discuss Aristotle's argument about the Sea Battle and his Conditional Necessity. In section 3 I argue that both the Conditional Necessity and the Necessity are applicable to future contingents from the perspective of factual necessity. Based on distinguishing between the context of utterance and the context of assessment, in section 4 I introduce a hypothetical truth-value of the future contingent and in section 5 I establish an "hypothesis-revision" interpretation about it. Section 6 is a conclusion of this discussion.

\section{ARISTOTLE'S ARGUMENT ON CONDITIONAL NECESSITY}

Aristotle's discussion about the Sea Battle in DeInterpretatione ix led him to a Conditional Necessity conclusion $(p \rightarrow \square p)$, i.e. "for everything, it happens necessarily when it happens; it does not happen necessarily when it does not happen". Aristotle emphasized the key to this conclusion is it is conditional and the distinction between it and another statement, "for everything, it happens necessarily or does not happen necessarily". But if we recognize the law of exclude middle ( $p \vee \neg p)$ is true universally, then we will move toward the deterministic camp, acknowledging the Necessity conclusion that everything happens necessarily or does not happen necessarily ( $\square p \vee \square \neg p$ ).

Then there is essentially no difference between the two statements. A traditional interpretation argues that the problem is caused by the law of excluded middle and to avoid the trap of determinism Aristotle rejected the applicability of it to the future contingents.

\footnotetext{
${ }^{1}$ See J. L. Ackrill (1987), pp. 17-19.
} 
$p$ Just can be a statement concerning a past or present event, otherwise the law is invalid. ${ }^{2}$

However, what Aristotle denied is not the law of excluded middle but the rule of Necessity, "everything takes place necessarily or does not take place necessarily", which can be applied only to what has happened or is happening and not to the future contingencies. Because what has happened or is happening is unchangeable, and our thinking and behavior can influence on the future. According to Aristotle's view, it can only be concluded that everything happens or does not happen necessarily, whether it has happened or is happening or has not happened. For instance, it is true to say that, as Aristotle said, "the sea battle will happen or not happen tomorrow necessarily" but not "it will inevitably happen tomorrow or impossibly happen tomorrow".

Under the premise of affirming the law, Aristotle insisted that it is much more reliable that talking about the conditional necessity of a future event than the necessity of it alone. But he did not realize that his Conditional Necessity actually contained the result of determinism. Aristotle concluded the future conditional necessity $(F p \rightarrow \square F p$ ) from the following premises:

- For a statement and its negation, one of them describes the fact in reality and is clearly a true statement while the other is a false one;

- Necessarily so, if (1). Then it is necessary for everything either to be the case or not to be the case;

- If something happens now, it was true to say earlier that it will happen, then its occurrence is necessary. Then for any moment before now, it will be necessary for its occurrence.

And because the occurrence of a past or present thing is immutable, it can be said that if something happens, then it happens necessarily. In modal logic, we can easily prove that this Conditional Necessity conclusion is not a theorem, so we cannot get the Necessity conclusion that everything happens according to necessity. Although Aristotle made it clear that the necessity conclusion is unsatisfactory and the rule, "everything takes place necessarily or does not take place necessarily", only can be applied to those things that have happened or are happening, as long as he admitted the validity of his so-called Conditional Necessity, it will inevitably lead him to the necessity of determinism. The cause of this problem of jumping into determinism is that the premise (3) is actually only suitable for the past or present events, and Aristotle mistakenly replaced them with things that have not happened in the future. He used the inevitability and unchangeability of past or present to demonstrate the inevitability of future contingencies. ${ }^{3}$ It seems to me, nevertheless, that this problem is not the essential one raised by Aristotle's discussion, and that how do we explain the "necessity" in his discussion of the Sea Battle is the more important issue. We seem to end up in the debate between determinism and indeterminism, but we will see that this is not the case.

\section{FACTUAL NECESSITY}

Two important aspects are involved in my discussion of Aristotle's Conditional Necessity conclusion. One is the basis for us to judge whether a proposition is true or false, and the other one is what Aristotle is standing on to explain the important concept of "necessity".

\footnotetext{
${ }^{2}$ A prevailing view argues that Aristotle regarded future contingents as neither true nor false and believed that Aristotle rejected the applicability of the law of exclude middle in the future tense. John P. Burgess (1978) considered that Aristotle gave a third, intermediate value to future contingents. JanŁukasiewicz (1920) introduced a third truth-value "undetermined". However, this three-valued logic approach is unreasonable and can lead to some intuitive results. According to Lukasiewicz's three-valued logic, for example, if the truth- values of the two propositions, "a sea battle will happen tomorrow" and "a sea battle will not happen tomorrow", are undetermined, the truth-value of "a sea battle will happen tomorrow or not happen tomorrow" has not yet been determined. ArthurPrior (1962), Peter Øhrstrømand Per F. V Hasle (1995) have refuted this. Aristotle also pointed out that a future accidental event must occur or not occur, so the disjunction of the corresponding two propositions must be true, although it is impossible to judge which one is true.

${ }^{3}$ In the Piercean system and the Ockhamist system of Prior (1967) and the Leibniz system of Øhrstrøm and Hasle (1995), the third premise cannot be a theorem. But $F p \rightarrow \square F p$ is a theorem of the Pierce system. But since $F p$ and $F \neg p$ are false in this system and Prior pointed out that $F \neg p$ is not equivalent to $\neg F p$, we will not end up in the determinism. Patrick Todd (2018) also argued that "a sea battle will not happen tomorrow" $(F \neg p)$ is not the negation of "a sea battle will happen tomorrow" $(F p)$ in the strict sense, so the disjunction of the two propositions is not an instance of $A \vee \neg A$.
} 
First of all, Aristotle's view on judging the truth-value of propositions reflects the idea of the correspondence theory of truth. The correspondence theory of truth expresses the correspondence between our cognition and object, thought and reality, and the relationship between real things (thoughts, beliefs, statements, etc.) and the reality they describe. We judge the truth of a proposition based on whether it accurately describes the fact in the real world. For instance, the proposition "snow is white" is true if and only if snow is white in reality. As Aristotle said, if someone asserts that something will take place and someone else denied it, there is no doubt that one of the two propositions will be consistent with the fact while the other one will be contrary to the fact. A key point here is that although the traditional correspondence theory of truth discusses a factual truth ${ }^{4}$, without considering the time factor, and the proposition describing truth is time-independent, the fact that the proposition is based on actually refers to what really is in the real world, something that has happened or is happening. When we say that a proposition is true, it means that the proposition expresses a fact, and the fact is something that is already unchangeable. Therefore, it can be said that what the traditional truth discusses is those propositions that match the facts that already are and have occurred. Secondly, according to Aristotle's interpretation of "necessity" and the basis for judging the truth-value of propositions, the proposition "snow is white" is true and "snow is necessarily white" is also true because snow is white in reality. If it is already a fact that snow is white, snow cannot fail to be white, that is to say, it is impossible that snow is not white. Snow must be white, so "snow is necessarily white" is true. And according to the rule that "everything takes place necessarily or does not take place necessarily", we can conclude that "snow is white necessarily or is not white necessarily" such a conclusion. However, jumping out of the limitation of the real world and logically speaking, both "everything takes place necessarily or does not take place necessarily" and "for everything, it happens necessarily when it happens; it does not happen necessarily when it does not happen" are not only do not apply to future contingencies, but also not applicable to what has happened or is happening.

The reason is that the "necessity" Aristotle talked about is essentially different from the necessity of modal logic. Modal logic defines it using "possible world", which is a logical necessity in the global sense. The real world is just one of possible worlds and all of the possible worlds should be taken into account when we consider the necessity of the occurrence of something. For everything, it is true to say that it happens necessarily only when it happens at all accessible possible worlds. For example, if "snow is necessarily white" is true, it means that snow is white at all accessible possible worlds, not just in the real world. But if we treat this proposition from Aristotle's explanation of "necessity", it is true in reality. Based on the real world, Aristotle used fact to define "necessity", which is a factual necessity in the local sense. That is, if the facts are so, then the facts must be. To talk about the necessity of something happens, we only need to consider the facts in the real world. As long as it happens, it can be said that it happens necessarily. If a proposition is true, then the event it describes is a fact. And if this event is a fact, the fact must be so, then the proposition that expresses this fact must be so is true. "Snow is necessarily white" only means that the snow in reality is white and cannot describe anything about other possible worlds. In the global sense, no matter what has not happened in the future or what has happened in the past or is happening now, it is impossible to draw a conclusion that an individual thing occurs necessarily from the occurrence of it. Because although "snow is white" is in line with the reality of the real world, there is no guarantee that snow is white at all other possible worlds. "Snow is white" has only factual necessity and does not have logical necessity. Therefore, when we discuss whether the occurrence of something in the future is necessary, we should pay attention to distinguishing these two different concepts of "necessity". If we explain "necessity" from the perspective of facts, the occurrence of something is necessary if and only if the occurrence of this matter is a fact. The rule of Necessity and the Conditional Necessity are applicable to the facts that have occurred.

We judge the truth and falsehood of a proposition and explain the necessity of something happens based on the facts in reality. Since the facts are those that actually have happened or are happening,

\footnotetext{
${ }^{4}$ Gottfried Wilhelm Leibniz (1969) distinguished between two kinds of truths, namely truths of reasoning and the truths of fact. The former truths refer to the truths of logic or mathematics and have logical necessity. They "are necessary, and their opposite is impossible". The latter truths refer to the natural laws in the real world and are factually necessary. They "are contingent, and their opposite is possible".

${ }^{5}$ The concept of "possible world" was first proposed by Leibniz, on which Kripke established the theory of possible world semantics.
} 
we still cannot explain the truth of future contingents and the necessity of future events. For a future contingent, there is no corresponding fact to match or contradict it, so its true and false cannot be judged. And we are not sure whether the event described by this proposition will become a fact, so we cannot make any necessary judgments on future events. But the Necessity and the Conditional Necessity can still indicate the factual necessary feature of future events. Because the occurrence of something in the future will either become or not become a fact and it is assumed that the occurrence of a certain event will become a fact when we assume that it occurs. For example, for the case of tomorrow's sea battle, both its occurrence and non-occurrence are not necessary because we can't be sure now that which one will become a fact, that is, we have no idea that whether the sea battle will happen tomorrow or it will not happen tomorrow. But what we can confirm is one of them will be a reality. Therefore, even though the truth of "a sea battle will happen tomorrow" and "a sea battle will not happen tomorrow" are uncertain and we cannot say that "a sea battle will happen necessarily tomorrow" and "a sea battle will not happen necessarily tomorrow", it must be admitted that "a sea battle will happen necessarily tomorrow or it will not happen necessarily tomorrow" and "a sea battle will happen necessarily tomorrow when it will happen tomorrow" are true.

Therefore, before arguing whether "everything takes place necessarily or does not take place necessarily" is a deterministic idea, we should first make a reasonable explanation of the "necessity". Whether we explain it in the sense of fact or in the sense of modal logic and whether it is a "factual necessity" or a "logical necessity". We have analyzed that the "necessity" discussed by Aristotle is not a necessity in the logically strict sense, but a factual necessity if he started from the facts in the real world. What the rule of Necessity expresses is that "the occurrence of an individual event is a fact or the non-occurrence of it is a fact". And this rule actually can be applied to both past and present unchangeable events and future contingencies.

\section{THE TRUTH AND FALSEHOOD OF FUTURE CONTINGENTS}

A following question is, how can we account for a future contingent that does not have a factual correspondence and cannot be judged to be true or false? And if we cannot judge its truth, does it make sense to expand this discussion and talk about something that has not happened in the future? Peirce and Prior argued that talking about the future is meaningless, and that only when the occurrence of a future event becomes a reality in the future can the corresponding proposition be true. It is true that "a sea battle will happen necessarily tomorrow" when we say that a sea battle will happen tomorrow is true. It seems that they also explained the "necessity" from the perspective of facts, the occurrence of an individual event is inevitable if its occurrence becomes a fact. But they held that before the occurrence of one thing becomes a reality, the corresponding future contingent are undecided, and it does not make sense to talk about it. William of Ockham (1969) believed that although it is impossible to obtain a true or false future proposition for the present moment in our cognitive range, from a God's eye point of view, it still has a certain truth-value. Strictly speaking, this is a deterministic thought.

John MacFarlane (2003) proposed a method for defining the truth-value of a proposition in two contexts, namely, a context of utterance and a context of assessment. ${ }^{6}$ The truth and falsehood of the proposition can only be judged by considering both the utterance context and the assessment context and is undetermined without one of them. He hoped to resolve the contradiction between determinacy intuition and indeterminacy intuition in this way. When the context of utterance and the context of assessment are the same context, those propositions about future contingencies are neither true nor false. When the context of assessment is later than the context of utterance, their truth depends on the assessment context. For example, we now say that "a sea battle will happen tomorrow", it is true (or false) if we evaluate the proposition tomorrow or after tomorrow and tomorrow's sea battle is (or is not) raging. But if the time of assessment is earlier than tomorrow, it is neither true nor false. This method essentially uses the context of utterance to limit the expression of a proposition, which can only point to a specific event in a decided context of utterance. If we evaluate the proposition after the time of the specific event, then this proposition is a future contingent for the context of utterance. However, it is a proposition about what has happened for the assessment context, and it can be determined true or false. And if the assessment context is before the time of the specific event, then

\footnotetext{
${ }^{6}$ The context of utterance refers to the context in which the speaking behavior occurs, and the context of assessment refers to the context in which the spoken proposition is evaluated.
} 
the proposition is a temporary accidental one for both utterance and assessment context and can be called strictly a future contingent.

Strictly speaking, a proposition itself does not have a truth-value and only in a specific context can it be judged whether it is true or false. It is meaningless to talk about the truth of a proposition alone. Thus, we need to fix a specific world to evaluate it. The traditional correspondence theory of truth defines the proposition's truth based on the context of the real world. In fact, when we say "snow is white" in daily life, what we express is that "snow is white in the real world". If a proposition involves time in it, however, the context in which the proposition is judged is not only the possible worlds, but also the time factor while fixing a world. For instance, in reality, the proposition "it rained yesterday" corresponds to different fact at different moment in time, with different truth. Its truth changes with time. Explaining the truth of a proposition involving time is more complicated than judging a normal time-independent proposition, because, for any moment in time, although the truthvalue of the proposition about what has happened in the past is certain, the truth of the future contingent cannot be judged. In addition, we usually evaluate a proposition at the same time as speaking or thinking about it. Consequently, I would say that the context of utterance is also the context of evaluating propositions. A problem with is that we cannot handle the future contingents gracefully.

But we can distinguish the two contexts, just like MacFarlane, to consider the truth of a future proposition. We can first fix the specific moment through the proposition and the context of utterance and then assess it after this moment. It will be the case that, in the same utterance context, "it rained yesterday" describes the same fact in different evaluation contexts. When we want to evaluate a future contingent in a context of utterance, we need to consider the assessment context, whereas the truth of a proposition about what has happened in the past in a utterance context is already determined. This is actually a way to turn future propositions into propositions about past events. The problem with this approach, however, is that it still does not well explain the truth-value of a future contingent in a strict sense, giving it a truth that is neither true nor false.

Then how do we account for the truth of a proposition if the moment of the evaluation context is earlier than the specific moment pointed to by the proposition and the utterance context? If we stop thinking and acting because we cannot predict the future, the future will be negatively affected to some extent. In fact, considering the future contingencies can guide our actions and influence the development of future. As Aristotle said, considerations and actions work for the future. But all future considerations are just speculations, and it is not decisive but influential for the future. A simple example will help. For two equal forces, Army A predicted that "a sea battle will happen tomorrow" the day before the sea battle and made a series of preparatory work, while Army B predicted that "a sea battle will not happen tomorrow" and did not take sufficient response measures. There are three possible outcomes of the sea battle, if this battle actually occurred: Army A won, Army B won, there is no victory for both sides. Regardless of other factors, Army A won is the most likely, but it cannot be said that this is an inevitable result. Therefore, although we can't determine the truth of propositions about future events, we can assume it, which has practical guidance and influence on future development.

It seems to me, moreover, although we assess a future contingent after the moment pointed to by it and the context of utterance and obtain a certain truth-value, the truth of this proposition is just hypothetical. For the real world, we still cannot predict whether future event corresponding to this proposition will become a fact. All that can be said is that the proposition is true in some assessment contexts and false in others. MacFarlane actually only gave a truth-value to future propositions through a hypothetical assessment context and this truth-value is only a hypothesis for the real world. For instance, we now say "It will rain tomorrow", then it is hypothetically true in reality for the assessment context of tomorrow and tomorrow's rain. Only when tomorrow really comes and the context of assessment is the "tomorrow" with the fact of raining, we can revise and determine the truth of this proposition based on the actual situation. I prefer to say that the future contingent has a hypothetical truth, rather than giving it a truth-value that is neither true nor false or determining it in some hypothetical context of assessment. Therefore, here we only divide two kind of assessment contexts from the perspective of time, with the moment pointed to by a proposition and an utterance context as the boundary point, that is, the context in which the event corresponding to the proposition does not occur before this moment and the context in which the event occurs at this moment or has occurred after it. 


\section{THE “HYPOTHESIS-REVISION" INTERPRETATION OF FUTURE CONTINGENTS" TRUTH-VALUE}

It must be realized that the future events and future contingents we talk about here are associated with the real world. Under the context of real world, the rest is, for us, to consider the context of utterance and assessment. For an utterance context, it has an unalterable past and multiple possible futures. Thus, we can directly determine the truth of those propositions that describe past and present. But for a proposition that describes an event that may or may not occur at some moment in the future, its truth can only be assumed before that moment and only after that moment can it be evaluated based on the actual fact. Only in such a real context of assessment can the truth-value be revised and even be determined. The assessment context of determining the proposition's truth should refer to the real context in reality, rather than some possible context that is assumed before the time comes and the event occurs actually, based on our cognitive ability.

We are talking about the past and the present that cannot be changed and an undetermined future when we consider the real world. Although the past is non-selective, for a certain moment in reality, there are many possible alterable futures. The real world, therefore, should be actually a collection of possible worlds, and a real possible world at a certain moment consists of the same past, present as the real world and a possible future. As time goes by, a moment in the future will become the present and even the past, hence the real world is a collection that changes with time. Suppose the proposition $p$ describes that it rains. For the real world at $t_{1}$ and raining at this moment, the real world is a collection of possible worlds $w_{1}$ and $w_{2}$. But since $t_{1}$ is the future momentof $t_{0}$ and it is possible to rain and not rain, the collection $\left\{w_{1}, w_{2}, w_{3}, w_{4}\right\}$ expresses the real world of $t_{0}$. So only when a specific time is fixed can we discuss a concrete collection of real possible worlds, and the real world has a certain past, present and many possible futures.

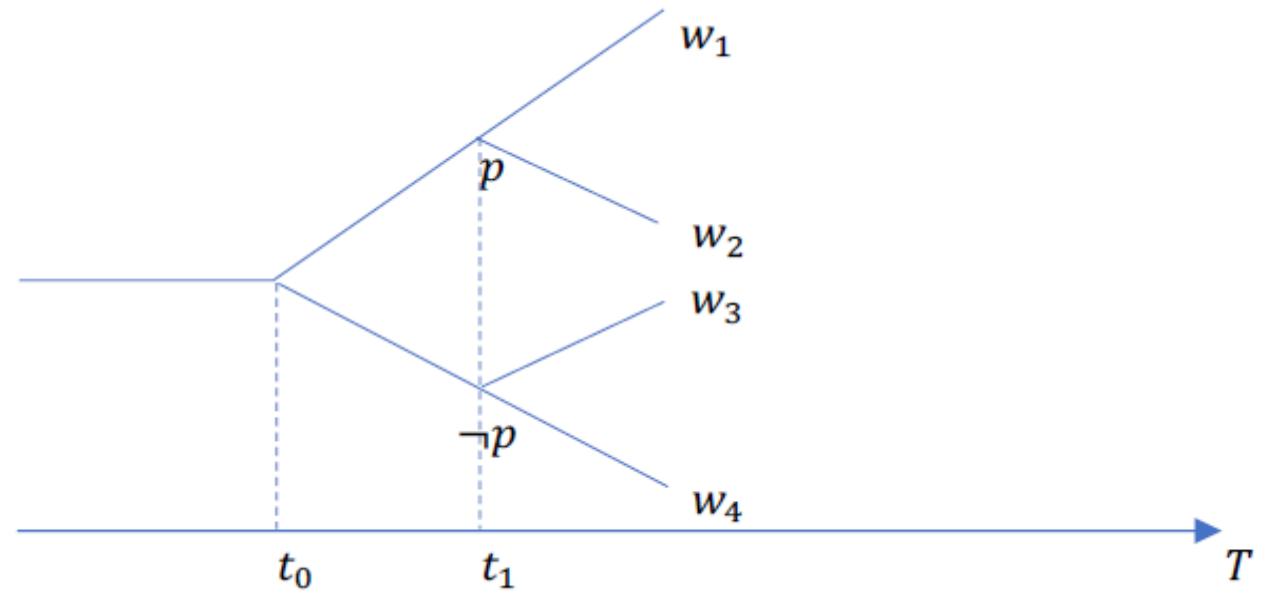

Figure1

Suppose we say that "it will be raining on the following $\mathrm{n}$-th day" (expressed by a formal formula $F(n) p$ ) at a certain moment $t_{0}$, which is the moment of an utterance context. This utterance and the moment of it, $t_{0}$, can express a specific future event that it will be raining at moment $t_{n}$. Here we use "day" as the unit of time and $n \in \mathbb{Z}, F(1) p$ means it will rain on the first day of the future, $F(2) p$ means it will rain on the second day of the future, ... If $F(n) p$ is evaluated at moment $t_{A}$ and $t_{A}<t_{n}$, the truth of it just can be made hypothetically. But if the assessment moment $t_{A} \geq t_{n}, F(n) p$ is actually a proposition about the past event that has occurred for the context of assessment, then its truth can be revised to a determined one.

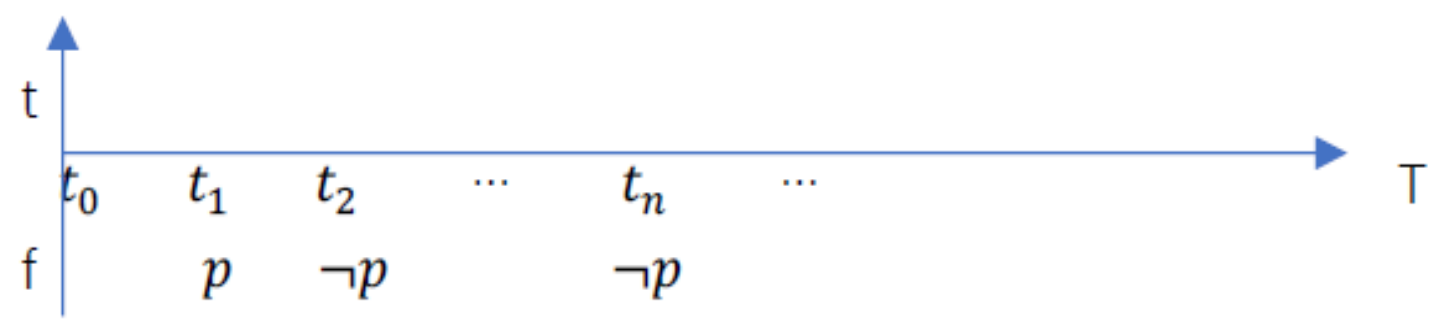

Figure2 
We evaluate $F(n) p$ at utterance moment $t_{0}$ with respect to the assessment moment $t_{A}$ and the occurrence of events in this context of assessment. Considering a true predicate $(\operatorname{Tr}), \operatorname{Tr} A$ indicates the proposition that proposition $A$ is true. Let $D=\{F(n) p \mid n \in \mathbb{N}\}$ be the set of propositions, and the interpretation of $\operatorname{Tr}(I(T r))$ is a set of propositions $(I(\operatorname{Tr}) \subseteq D)$. Since the truth-value of the future contingents changes with the changing context of assessment, $I(T r)$ will also change with it. Suppose $X$ is the initial interpretation of $\operatorname{Tr}$ when the evaluation moment is $t_{0}$ and $\delta(\delta(X) \in D)$ is a function that revises the interpretation of $T r$. The interpretation is revised once when the rain actually occurs on the first day after $t_{0}$ and $\mathrm{n}$ times at the evaluation moment $t_{n}$ according to the actual situation.

If $t_{A}=t_{1}$, then $F(1) p \in \delta(X)$ (no matter $F(1) p \in X$ or $\left.F(1) p \notin X\right)$;

If $t_{A}=t_{2}$, then $F(1) p \in \delta^{2}(X)$ and $F(2) p \notin \delta^{2}(X)$ (no matter $F(1) p, F(2) p \in X$ or $F(1) p, F(2) p \notin$ $X, F(2) p \in \delta(X)$ or $F(2) p \notin \delta(X))$;

...

If $t_{A}=t_{n}, \quad$ then $\quad F(1) p \in \delta^{n}(X), F(2) p \notin \delta^{n}(X), \ldots \ldots, F(n) p \notin \delta^{n}(X)$ (no $\quad$ matter $F(1) p, F(2) p, \ldots, F(n) p \in X$ or $\quad F(1) p, F(2) p, \ldots, F(n) p \notin X, F(2) p, \ldots, F(n) p \in \delta(X) \quad$ or $F(2) p, \ldots, F(n) p \notin \delta(X), \ldots, F(n) p \in \delta^{n-1}(X)$ or $\left.F(n) p \notin \delta^{n-1}(X)\right)$;

$\cdots$

It can be determined whether $F(n) p$ is in the interpretation of $T r$ when $t_{A}=t_{m}$ and $m \geq n$, and we can only assume $F(n) p \notin I(T r)$ or $F(n) p \in I(T r)$ when $t_{A}=t_{m}$ and $m<n$.

Thus, regardless of whether the initial assumptions about the future contingents are true or false, as time progresses, all presuppositions of future events will gradually be confirmed or falsified. Then the truth-value of more and more propositions will also be revised and confirmed. Before confirming the proposition's truth-value, we can say that it is true hypothetically and it is false hypothetically.

\section{CONCLUSiON}

Aristotle provoked a debate about determinism and indeterminism about whether a sea battle will necessarily happen tomorrow. Because "necessity" is a crucial concept in his argument on the Sea Battle, we first need to find out in what sense he discussed this concept. If Aristotle's "necessity" refers to the logical necessity in the logically strict sense, then he will indeed fall into the predicament of determinism. As far as the logical necessity is concerned, for those things that have happened in the past or are happening in the present, their occurrence is not inevitable, and the corresponding propositions are true but not necessarily true. In fact, however, starting from the real world, Aristotle used the "facts" to judge the truth and falsehood of a proposition and explain the "necessity". What he talked about is the factual necessity, so everything that has happened or is happening happens necessarily and the corresponding proposition is true and necessarily true. For the propositions about future events, we can only say that they are true or false, necessarily true or necessarily false, hypothetically true, and hypothetically false. From the perspective of factual necessity, it must be admitted that the rule of Necessity, "everything takes place necessarily or does not take place necessarily", and the Conditional Necessity, "for everything, it happens necessarily when it happens; it does not happen necessarily when it does not happen", are applicable to what has happened and what has not happened. Because what they mean is actually "the occurrence of something is a fact or the non-occurrence of it is a fact" and "If something happens, then its occurrence is a fact".

In addition, a proposition only has a truth-value in a particular context. For a proposition that does not involve time, we only care about whether it accurately describes something in a certain possible world. For propositions involving time, nevertheless, the context in which the truth is discussed is not just the possible world, but also the context of utterance and assessment. In a certain possible world, only in a particular utterance context can a proposition correspond to a specific event, and the truth and falsehood of the proposition can be judged according to what happens in this world. The important point here is that when a proposition describes something that does not happen in a certain context of utterance, we need to consider the context of assessment. If the moment of assessment context is before the moment when this future event occurs or does not occur, then the proposition's truth can only be assumed. And if we evaluate the proposition after the event occurs or does not occur, we can determine its truth-value. 


\section{REFERENCES}

[1] J. L. Ackrill, A new Aristotle Reader, Clarendon Press, Oxford, 1987.

[2] John P. Burgess, The Unreal Future, Theoria, 1978, Vol. 44, $157 \mathrm{ff}$.

[3] Jan Łukasiewicz, Three-valued Logic, RuchFilozoficzny, 1920, Vol5.

[4] Arthur Prior, Past, Present and Future, Oxford University Press, 1967.

[5] Peter Øhrstrøm and Per F. V Hasle, Temporal Logic: from Ancient Ideas to Artificial Intelligence, Kluwer Academic Publishers, 1995.

[6] Patrick Todd, The problem of future contingents: scoping out a solution, Synthese, 2018.

[7] Gottfried Wilhelm Leibniz, Philosophical Papers and Letters (edited by Leroy E. Loemker), Kluwer Academic Publishers, 1969.

[8] William of Ockham, Predestination, God's Foreknowledge, and Future Contingents, Translated by Marilyn McCord Adams and Norman Kretzmann, 1969.

[9] John MacFarlane, Future Contingents and Relative Truth, The Philosophical Quarterly, 2003, Vol. 53, No. 212: 321-336.

[10] Jaakko Hintikka, The Once and Future Sea Fight: Aristotle's Discussion of Future Contingents. In De InterpretationeIX, The Philosophical Review,1964, Vol. 73, No. 4: 461-492.

[11] Michael Perloff; NuelBelnap, Future Contingents and the Battle Tomorrow, The Review of Metaphysics, 2011, 64, 3: 581-602.

\section{AUTHOR BIOGRAPHY}

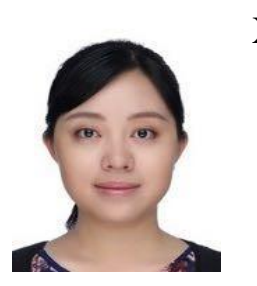

Xuejun Wang, School of Philosophy, Beijing Normal University

Citation: Xuejun Wang. "A Study of Interpreting the Future Contingents". International Journal of Humanities Social Sciences and Education (IJHSSE), vol. 6, no.10, 2019, pp. 1-8. doi: http://dx.doi.org/10. 20431/2349-0381.0611001.

Copyright: (C) 2019 Authors. This is an open-access article distributed under the terms of the Creative Commons Attribution License, which permits unrestricted use, distribution, and reproduction in any medium, provided the original author and source are credited. 